\title{
Retraction Note to: Mononuclear Cu Complexes Based on Nitrogen Heterocyclic Carbene: A Comprehensive Review
}

\author{
Sina Matavos-Aramyan ${ }^{1}$ (D) Sadaf Soukhakian ${ }^{1}$. \\ Mohammad Hossein Jazebizadeh ${ }^{1}$
}

Published online: 2 September 2020

(c) Springer Nature Switzerland AG 2020

\section{Retraction to: Topics in Current Chemistry (2020) 378:39 https://doi. org/10.1007/s41061-020-00304-8}

The Editor-in-Chief has retracted this article [1] because it shows significant overlap with a previously published article [2].

None of the authors have responded to any correspondence from the publisher about this retraction.

\section{References}

1. Matavos-Aramyan S, Soukhakian S, Jazebizadeh MH (2020) Mononuclear Cu complexes based on nitrogen heterocyclic carbene: a comprehensive review. Top Curr Chem 378:39. https://doi. org/10.1007/s41061-020-00304-8

2. Danopoulos AA, Simler T, Braunstein P (2019) N-Heterocyclic carbene complexes of copper, nickel, and cobalt. Chem Rev 119:3730-3961. https://doi.org/10.1021/acs.chemrev.8b00505

Publisher's Note Springer Nature remains neutral with regard to jurisdictional claims in published maps and institutional affiliations.

The original article can be found online at https://doi.org/10.1007/s41061-020-00304-8.

Sina Matavos-Aramyan

matavos@repf.info

1 Research and Development Department, Division of Chemistry, Raazi Environmental Protection

Foundation, Shiraz, Iran 